\title{
Do Suppliers Still Have Hidden Reserves To Enhance Clients' Satisfaction? Factors Affecting Perceived Risk In The Project-Type Services
}

\author{
Éva Nádor, Budapest Business School, Hungary
}

\begin{abstract}
The current economic downturn is affecting innovation unfavourably and the accelerating changes of the global economy call for ongoing innovation. Successful firms seize the opportunity to maintain the competitive advantage with the help of increased spending on innovation. In general terms, innovation is evidently increasing the perceived risk of the sellers and the buyers. This is even more true in the case of services due to the bilateral performance risk and the process-like nature. The latter means that the success of a service transaction is uncertain until it is completed. As the project buyer lacks the required knowledge to complete the project, the major risk is related to the supplier's expected performance. The risk perceived by a client has a negative effect on client satisfaction and therefore might directly jeopardize the success of marketing. This is why the effective management of the perceived risk is of high importance. The key to that is in the clear knowledge of the nature of the perceived risk. So far research has given only a few answers to how the performance risk perceived in a service transaction can be handled. The author is going to present a working paper about the research launched in 2010 conveying the foregoing research results. The research is focusing on competence-based perceived risk of the projects' actors. The research helps develop a conceptual model on the risk perception of the buyers. The ultimate objective of the research is to help the suppliers develop an effective risk management process.
\end{abstract}

Keywords: Project Risk; Perceived Risk; Organisational Capabilities; Risk Management; Critical Project Incidents; Interactive Communication

\section{INTRODUCTION}

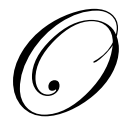

ne way or another, all means of marketing are focused on client satisfaction, which became even more important during the last decade characterized by increased competition. Due to the tough competitive market situation and the constantly changing market environment, both manufacturers and trading companies are forced to keep innovating. The higher degree of innovation increases the uncertainty of the sellers and buyers. Innovation is always calling for a high amount of investments; therefore, companies are striving to decrease the risk of business. Researches in the field of consumer goods have already made significant progress in risk analysis. Far less attention has, however, been devoted to the B2B field, particularly for project-type services. Our research is aiming to fill this gap.

Taking into account that projects are always aiming to achieve a certain result, we are focusing on the risk related to the supplier's performance. The buyer is purchasing value, more precisely competence-based advantages. The more process-oriented the business, the higher the level of interaction required.

There is an ongoing interaction between the buyer and the seller, which is highly affected by the perceived risk. Another challenge results from the fact that the projects are unique. The constantly new business problems 
increase the perceived risk of both sides. The issue of the level of risk is further complicated by the possibility of its dramatic shift during the course of the services. The information and knowledge asymmetry between the actors is also challenging to both parties.

Effective risk management is possible in case the actors know the nature of the risk and the most effective marketing tools to decrease this risk.

\section{THEORETICAL BACKGROUND}

We are considering projects as series of actions to achieve specific goals within a certain time frame, with dedicated resources, under a strictly defined budget.

This definition allows the inclusion of a wide range of services, such as engineering consulting, business consulting, ad-hoc market research, management of advertising campaigns, and event management. Besides bearing the service characters, all of these business areas are typically discontinous, unique and complex.

In risk analysis, the best starting point is the review of the project process. The Cova-Ghauri-Salle process model is interpreting the process from the pre-tender phase to contracting. By their model, the supplier is constantly developing its competences and relationship network.

In terms of interactivity and interdependence between the actors, Cova and Salle (2007) point out the possible synergies between the marketing of solutions and project marketing. Some of the authors revealed that the level of interdependence is highly influenced by project type. Bankvall, Bygballe, Dubois and Jahre (2010) directed their attention toward the different types of interdependence existing in the construction projects. Beyond sequential interdependence, they point out two more types of interdependence and prove their existence by research. One of them derives from joint utilization of resources and the other from coordination of activities at the construction site.

Titus and Bröchner (2005) investigated the role which information plays in a complex network, such as construction procurement, expressing that the coordination within partners and integration across partners are critical in effective project management. Professional services, such as business consulting, are also characterised by highly interactive relationships. Lowendahl (2000) discusses the challenges resulting from the interaction, pointing out that in addition to that, there is a challenge involved in the interdependence between the supplier and the buyer in terms of the inputs as well.

Jacoby and Kaplan (1972) discuss the determinants of perceived risk, such as 1) heterogeneity of the offer (Veres, 2009), 2) buyer-supplier interaction, 3) price, 4) company image, 5) personality of decision makers, and 6) history of seller-buyer relationship (Ganesan, 1994).

In general, studies have found that buyers' perceived performance risk is linked to presumed weaknesses of the supplier (Veres, 2009), but information on a particular supplier's competence profile reduces the buyers' market uncertainty - in the pre-transaction phase - (Golfetto \& Gibbert, 2006) and its transaction uncertainty - in the implementation phase - (Ford, 2002).

Golfetto and Gibbert discuss the notion of marketing competencies in buyer-supplier relationships and the role these competencies play in creating value for the customer. The perceived risk can be managed through targeted communication - marketing of competences - which leads to an increase in the buyer's satisfaction. (Golfetto, Gibbert, 2006). Golfetto and Gibbert (2006) emphasize the marketing of competences, which deals with the utilization, promotion and "selling" of these competences in organizational contexts (Gibbert, Golfetto, \& Zerbini, 2006). Morgan and Hunt (1994) discuss another aspect of perceived risk identifying commitment and trust as key mediating variables in buyer-seller relationships. Trust is the sine qua non for building relationships and in client retention. (Kotler-Hayes-Bloom, 2002) Gluckler (2003) is expressing thatexperience-based trust is an important tool in decreasing uncertainties. 


\section{RESEARCH METHODS}

A complex research project was launched in 2010. The three-year research consists of the following phases:

- $\quad$ exploring qualitative research based on in-depth interviews

- $\quad$ quantitative survey based on conjoint analysis

- $\quad$ post-quantitative and qualitative research, including international comparative research

Our research objective is to reveal the nature of the competence-based perceived risk and to answer how the risk perceived in a service transaction can be handled. This research objective involves the following research questions:

RQ1: What are the main expectations of the actors in terms of capabilities?

RQ2: How can we characterize the changing risk level during the process?

RQ3: What are the main information sources of the actors regarding the partner?

RQ4: How does the bilateral risk appear in the project, and what are the major differences regarding the actors?

RQ5: How can the actors decrease the perceived risk of the partner?

Our hypotheses include the expected and presumed capabilities, the efficiency of communication, and the special character of different project fields. The key hypotheses have been formulated as follows:

H1: There are significant differences in the expected capabilities by the business sectors, the tangible contents of the project, and history of the relationship.

H2: $\quad$ Presumed capabilities are reducing the perceived risk on both sides.

H3: Effective communication is reducing the perceived risk of the actors.

H4: The nature of the perceived risk is significantly different among the two ends of the project - hard projects (hardware, buildings) and soft projects (consulting, ad hoc market research).

In order to achieve the research objectives, both qualitative and quantitative researches are adapted. This research paper presents the key findings of the qualitative research. Based on the findings of the qualitative researches, we will build a conceptual model on the value and risk perception of the buyers and sellers. As the final part of the research project, a quantitative study will be undertaken.

In the qualitative phase, 129 structured in-depth interviews were carried out - 49 interviews with the managers of hard projects and 80 of soft projects. Differentiation between the two types was made on the physical content of the project. On the hard project market, we interviewed mostly building and fitting companies and property developers. On the soft project market, IT companies, consulting firms, market research companies, and advertising and media agencies were included. Our interview partners were middle managers with extensive project experiences.

In the first phase of the in-depth interviews, we asked the managers to define the most important competences they expect from the partner. The spontaneous analysis revealed the presumed capabilities of the partner. The interviewees were asked to list the most important expectations in terms of the partner's capabilities. In the critical incident analysis, we asked the actor to recall events with positive and negative outlooks in the preparation phase. We wanted to know what project events forecasted the success and failure of the project. The last 
part of the interview was aided by classification of the partner's capabilities with the help of cards, grouping the given capabilities by importance.

\section{KEY RESEARCH FINDINGS}

\section{Expected Capabilities}

The interviews show that the middle managers are consciously dealing with project risks and risk management. Both the suppliers and buyers are making an effort to identify risk and find the best tools to decrease it.

As shown in Table 1, some of the expectations, such as reliability, motivation, trust, and commitment, are important for both actors. Suppliers' priority is solvency and they mentioned the need for clear problem definition. The in-depth interviews revealed that lack of clear problem definition by the client involves future misunderstandings and conflicts. Since many problems can occur during the course of the project, the conflictsolving capability of the buyer is also of high importance. A good partner relationship was also mentioned by the suppliers.

All buyers emphasized the competences and experiences of the suppliers as the most important expected capabilities. Their decision is highly influenced by the experiences and human resources of the suppliers. Table 1 shows the results of the qualitative research.

Table 1: Most Important Capabilities Expected by the Actors

\begin{tabular}{|l|c|c|c|}
\hline & Suppliers & Buyers & Both Actors \\
\hline Trust & & & X \\
\hline Motivation & & & X \\
\hline Commitment & & & X \\
\hline Solvency & $\mathrm{X}$ & & \\
\hline Clear problem definition & $\mathrm{X}$ & & \\
\hline Information & $\mathrm{X}$ & & \\
\hline Competences & & $\mathrm{X}$ & \\
\hline Experiences & & $\mathrm{X}$ & \\
\hline
\end{tabular}

Source: Own edition

Differences regarding expected capabilities were not remarkable between hard and soft projects; however, trust and creativity of the suppliers seemed to be more important in soft projects.

Risk of the actors can be reduced by information. The more information the actors have, the less risk they face. Research results show that both suppliers and buyers are working hard to obtain information about the partner. The source of information is different between hard and soft projects.

In hard projects the suppliers are primarily looking for public company data on the potential buyer. In addition, they also try to get information through their business networks. The most important information sources for buyers are references and recommendations. Former experiences also play a big role in the decision-making; therefore, buyers prefer previous project partners. In building projects, the buyers generally prefer to visit the construction site of the potential supplier.

In soft projects, the suppliers try to obtain information about the buyers from company data and through their business network. Information provided by the partner and internet are also considered useful. Buyers also use different information sources. The most important sources are references, proposals, and personal impressions. Public data and network information is also remarkable. 


\section{Critical Incident Analysis}

Based on in-depth interviews, we can say that project actors can foresee the success of a project already in the pre-tender phase. In most cases, the professional expertise and the commitment of the partner become apparent in the first meeting and the financial situation can also usually be gauged. The contracting phase is also a good indication for the partners regarding future cooperation. The lack of a mutually beneficial contract anticipates difficulties in future cooperation.

In-depth interviews with managers of hard projects show that critical incidents in the course of implementation mostly derive from technical and legal difficulties that arise. In cases where it is possible to solve these problems, the projects will be accomplished. The interviewees stated that most projects come to an acceptable conclusion.

In the case of soft projects, the successful implementation is more probable. Suppliers of soft projects mentioned that in cases where the risk level seems to be high, they don't take the assignment. Therefore, there is generally less risk during the project and the risks are easier to handle. There is a very close, interactive relationship among the actors which ensures that problems come to light earlier and that cooperation supports the solution.

Generally due to bad management, there are also assignments with higher risk than average. Buyers' opinions suggest that behind unsuccessful projects, the weakness tends to be found in human resources. Juniors are often assigned to projects in order to improve cost efficiencies.

\section{Ranking of Competences}

In the last part of the interview, the managers were asked to evaluate 20 project competences. They had to rank competences by grouping them into three categories - high, average and low importance. The most frequently mentioned capabilities are shown in Table 2.

Table 2: Ranking of Competence Cards

$100=$ number of respondents

\begin{tabular}{|c|c|c|c|c|}
\hline & Extreme Importance & Average Importance & Low Importance & Not Chosen \\
\hline Professional expertise & 69 & 22 & 5 & 4 \\
\hline Communication & 68 & 26 & 2 & 4 \\
\hline Credibility & 66 & 27 & 3 & 4 \\
\hline Financial credibility & 60 & 22 & 10 & 8 \\
\hline Human resources & 60 & 25 & 9 & 6 \\
\hline Project management capability & 57 & 30 & 6 & 7 \\
\hline Ethical behaviour & 52 & 38 & 5 & 5 \\
\hline Financial resources & 49 & 30 & 9 & 12 \\
\hline Authorization & 47 & 25 & 14 & 14 \\
\hline Conflict solving capability & 45 & 43 & 7 & 5 \\
\hline Innovation capability & 41 & 28 & 23 & 8 \\
\hline Relationship management & 32 & 48 & 14 & 6 \\
\hline Recognizing own limits & 29 & 48 & 15 & 8 \\
\hline Materials used & 23 & 28 & 40 & 9 \\
\hline Company image & 23 & 42 & 28 & 7 \\
\hline Delegation of responsibility & 21 & 41 & 29 & 9 \\
\hline
\end{tabular}

Source: Own editing

Regarding the actors' position, the expected competences are different. The most important ones mentioned by the suppliers are financial reliability, communication, expertise, credibility, financial resources, human resources, and project management capabilities. On the buyers' side, credibility of the supplier, expertise, human resources, communication, project management capabilities, ethical behaviour, and innovation capability were mentioned as extremely important. 


\section{CONCLUSION}

The qualitative research helped us to better understand the content, importance, and role of the competences in the development of the perceived risk. Research findings provide us with a good tool to define the most effective tools of risk management in the various project phases. The research explored how to handle risk of the partner in the pre-tender phase, during the course of the project, and after the project is accomplished. It is obvious that the knowledge of the perceived risk of the buyers can encourage the proactivity of the suppliers. The research results show that the buyers appreciate the proactive approach of the suppliers. In the quantitative phase of our research, we will start from the conceptual model which classifies the projects based on the output (hard or soft) and the level of partners' involvement.

\section{ACKNOWLEDGEMENT}

The research was supported by the Hungarian Scientific Research Fund. No:81565.

\section{AUTHOR INFORMATION}

Éva Nádor is a professor of marketing at the Budapest Business School. She graduated with an M.A. in economics from the University of Economics Budapest, and obtained a Ph.D. in organisational sciences from the Miskolc University. She worked for 15 years in research, 10 years in marketing positions at multinationals before getting faculty position at the Budapest Business School. She is also acting as visiting lecturer at different universities in Europe. In addition to her work as a teacher and author, she has an extensive consulting experience with service businesses. E-mail: nador.eva@kkfk.bgf.hu

\section{REFERENCES}

1. Bankvall, L., Bygballe, L.E, Dubois, A., Jahre, M. (2010). Interdependence in supply chains and projects in construction. Supply Chain Management: An International Journal, 15(5), 385-393.

2. Cova, B. \& Salle, R. (2007). Introduction to the IMM special issue on 'Project marketing and the marketing of solutions'. A comprehensive approach to project marketing and the marketing solutions. Industrial Marketing Management, 36(2), 138-146.

3. Ganesan, S. (1994). Determinants of long-term orientation in buyer-seller relationships. Journal of Marketing, 58(April), 1-19.

4. Gibbert, M., Golfetto, F., \& Zerbini, F. (2006). What do we mean by marketing competences? A reply to Hooley et al. Journal of Business Research, 59(1), 148-151.

5. Golfetto, F., \& Gibbert, M. (2006). Marketing competences and the sources of customer value in business markets. Industrial Marketing Management, 35(8), 904-912.

6. Gluckler, J., Armbuster,T(2003) Bridging uncertainty in management consulting: the mechanisms of trust and networked reputation. Organization Studies, 2003. February

7. Jacoby.J. \& Kaplan, L. B. (1972). The components of perceived risk. Paper presented at the Conference of the Association for Consumer Research, Chicago.

8. $\quad$ Kotler, Ph., Hayes, T., Bloom, P.N. (2002). Marketing of professional services. Prentice Hall Press.

9. Lowendahl, B.R. (2000). Strategic Management of Professional Services Firm. Handelshojskolens Forlag, Copenhagen.

10. Morgan, R. M., \& Hunt, S. D. (1994). The commitment-trust theory of relationship marketing. Journal of Marketing, 58(3), 20-38.

11. Titus, S., Bröchner, J. (2005). Managing information flow in construction supply chains, Construction Innovation: Information, Process, Management, 5(2), 71 - 82

12. Veres, Z. (2009) Competence-based risk perception in the project business. The Journal of Business and Industrial Marketing, 24(3-4), 237-244. 